\title{
Water Soluble, Chiral, Verdazyl Radicals Derived From
}

\section{Aldoses}

\author{
Thanh-Ngoc Le, Harjot Grewal, Victor Changoco, Vinhly Truong and David J. R. Brook*
}

Department of Chemistry, San José State University, One Washington Square, San José, CA 95192

david.brook@sjsu.edu

\section{Graphical Abstract}

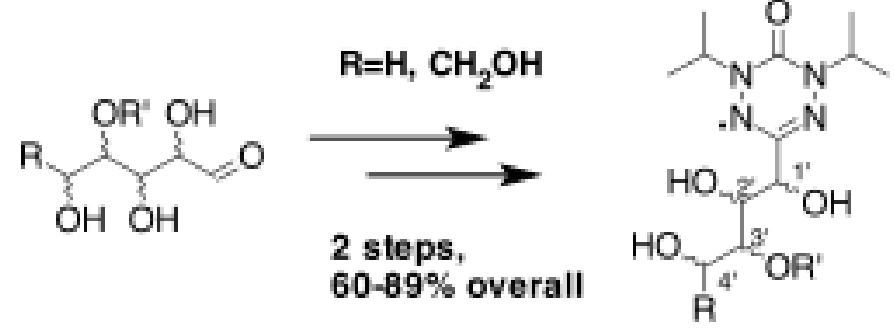

\begin{abstract}
Condensation of 2,4-diisopropylcarbonobis(hydrazide) bis-hydrochloride with a series of aldoses gives rise to tetrazanes that can be oxidized with potassium ferricyanide to give stable verdazyl radicals in good yield. The radicals are stable under ambient conditions, and are soluble in water and polar organic solvents. Aqueous solutions are stable over a range of both acidic and basic $\mathrm{pH}$ and do not react significantly with ascorbic acid or hydrogen peroxide. The radicals quench fluorescence from long lived fluorophores such as pyrene, or when there is an association between the radicals and the fluorophore. These radicals thus provide the foundations of a new series of radical probes and fluorescence quenchers.
\end{abstract}


Keywords. Stable Free Radical, Fluorescence quencher, Spin-probe, Verdazyl, Water Soluble.

\section{Introduction}

Stable free radicals are important tools for probing structure and function of biological systems. In addition to the identification of radicals in a diamagnetic background by EPR, radicals can be spatially located through ESR imaging, ${ }^{1-2}$ and can be indirectly detected through their ability as efficient fluorescence quenchers. ${ }^{3-11}$ and through NMR spin relaxation techniques ${ }^{12-16}$ In particular, the return of fluorescence combined with loss of an ESR signal when a free radical is destroyed is a powerful method for the detection of various species; recent examples include urushiols, ${ }^{17}$ ascorbic acid ${ }^{18-20}$ and nicotine. ${ }^{21}$ Attachment of radicals to a dendrimer core has been recently used to provide a novel, gadolinium free MRI contrast agent. ${ }^{22}$ As the most widely known series of stable organic radicals, nitroxides have played a dominant role in these studies; however, they are not without problems. A particular challenge is stability. Nitroxides are reduced to hydroxylamines in-vivo with a half life of a few minutes. ${ }^{23-24}$ Bulky substituents can reduce the rate of reduction, but limit the interaction with the system of interest. Consequently development of other stable radicals with different structure and reactivity may broaden the range of application of these methods. Verdazyls (Figure 1) are a series of paramagnetic, heterocyclic free radicals that are stable under ambient conditions and may provide an alternate series of radical probes with complementary properties to existing systems.

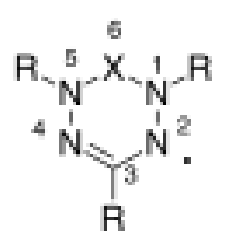

Figure 1. Structure of verdazyl free radicals

6-Oxoverdazyls $(\mathrm{X}=\mathrm{O})$ are generally more resistant to reduction than nitroxides, and variable substituents in the 1, 3 and 5 positions may be used to control interactions with other molecules. Of such interactions water solubility is desirable for biological applications, but most stable organic radicals are 
relatively non-polar as a result of the alkyl or aryl substituents required for stability. For verdazyls, several approaches have been used to improve water solubility. Early on in the study of verdazyls, Kuhn and Fischer-Schwarz reported water soluble verdazyls derived from sugar formazans. ${ }^{25}$ The water solubility was limited to about $10^{-5} \mathrm{~mol} \cdot \mathrm{L}^{-1}$ and the radical underwent disproportionation below $\mathrm{pH} 7$. Two groups reported water solubility derived from anionic substituents: Bezvershenko and Premyslov synthesized a sulfonated verdazyl radical with solubility in water of about $0.1 \mathrm{~mol} \cdot \mathrm{L}^{-1} \cdot{ }^{26}$ More recently, Hicks and coworkers synthesized a verdazyl carboxylic acid ${ }^{27}$ though this was only soluble in aqueous base. With our development of the more robust diisopropyl-6-oxoverdazyls ${ }^{28}$ we considered that Kuhn's approach of synthesizing verdazyls from aldoses was worth revisiting. We have reported initial studies in this area at recent conferences; ${ }^{29-30}$ we now report full details of the synthesis of a series of verdazyl radicals synthesized from aldoses, along with initial studies of their reactivity and properties as fluorescence quenchers.

\section{Results}

Combination of a series of aldoses (Table 1) with 2,4-diisopropyl carbono-bis-hydrazide (1) and sodium acetate in water gave tetrazanes 2a-i. Tetrazanes derived from the disaccharides maltose and lactose had complex ${ }^{1} \mathrm{H}$ NMR that may be indicative of more than one species in solution (as indicated by the number of peaks corresponding to isopropyl methyl groups); nevertheless, mass spectra were consistent with the tetrazane structure. Initial attempts at oxidation of the tetrazanes with benzoquinone $^{28,31}$ or sodium periodate ${ }^{32}$ failed; the former because of the limited solubility of the tetrazanes in non-aqueous systems, the latter because periodate oxidation also resulted in cleavage of the carbohydrate side chain. Oxidation with potassium ferricyanide, ${ }^{33}$ however, gave the verdazyls 3a-i as bright yellow solids, purified by extraction with butanol. (Scheme 1). While the disaccharide tetrazanes 2h-i clearly gave verdazyl radicals $\mathbf{3 h}-\mathbf{i}$ (as indicated by ESR, UV-vis and HRMS), HPLC indicated other components to the samples that could not be easily separated. 


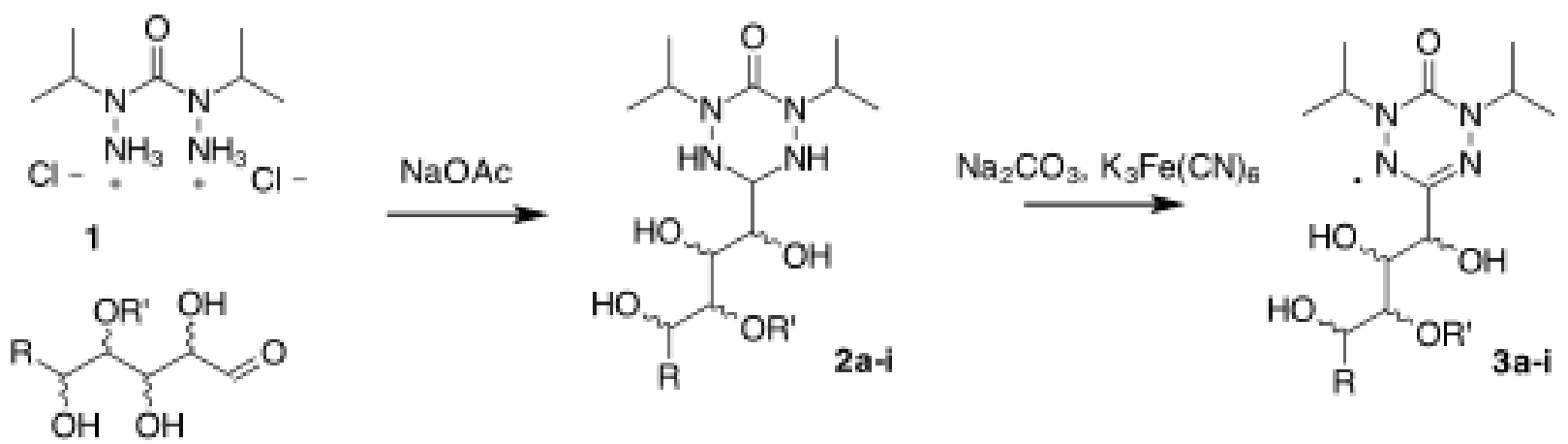

Scheme 1. Synthesis of tetrazanes 2a-i and verdazyls 3a-i. Absolute configurations of the stereocenters on the side chain are given in table 1.

Table 1. Starting aldoses, structure designations and absolute configurations of tetrazanes $2 \mathbf{2}-\mathbf{i}$ and verdazyls 3a-i.

\begin{tabular}{lcccc}
\multicolumn{1}{c}{ Aldose } & Designation & R & $\mathbf{R}^{\prime}$ & \multicolumn{1}{c}{$\begin{array}{c}\text { Absolute } \\
\text { Configuration }\end{array}$} \\
\hline D-Lyxose & $\mathrm{a}$ & $-\mathrm{H}$ & $-\mathrm{H}$ & $1^{\prime} \mathrm{R}, 2^{\prime} \mathrm{R}, 3^{\prime} \mathrm{R}$ \\
D-Xylose & $\mathrm{b}$ & $-\mathrm{H}$ & $-\mathrm{H}$ & $1^{\prime} \mathrm{S}, 2^{\prime} \mathrm{R}, 3^{\prime} \mathrm{R}$ \\
D-Ribose & $\mathrm{c}$ & $-\mathrm{H}$ & $-\mathrm{H}$ & $1^{\prime} \mathrm{R}, 2^{\prime} \mathrm{S}, 3^{\prime} \mathrm{R}$ \\
D-Arabinose & $\mathrm{d}$ & $-\mathrm{H}$ & $-\mathrm{H}$ & $1^{\prime} \mathrm{S}, 2^{\prime} \mathrm{S}, 3^{\prime} \mathrm{R}$ \\
D-Glucose & $\mathrm{e}$ & $-\mathrm{CH}_{2} \mathrm{OH}$ & $-\mathrm{H}$ & $1^{\prime} \mathrm{S}, 2^{\prime} \mathrm{R}, 3^{\prime} \mathrm{R}, 4^{\prime} \mathrm{R}$ \\
D-Mannose & $\mathrm{f}$ & $-\mathrm{CH}_{2} \mathrm{OH}$ & $-\mathrm{H}$ & $1^{\prime} \mathrm{R}, 2^{\prime} \mathrm{R}, 3^{\prime} \mathrm{R}, 4^{\prime} \mathrm{R}$ \\
D-Galactose & $\mathrm{g}$ & $-\mathrm{CH}_{2} \mathrm{OH}$ & $-\mathrm{H}$ & $1^{\prime} \mathrm{S}, 2^{\prime} \mathrm{R}, 3^{\prime} \mathrm{S}, 4^{\prime} \mathrm{R}$ \\
D-Maltose & $\mathrm{h}$ & $-\mathrm{CH}_{2} \mathrm{OH}$ & $-\alpha-\mathrm{D}-$ & $1^{\prime} \mathrm{S}, 2^{\prime} \mathrm{R}, 3^{\prime} \mathrm{R}, 4^{\prime} \mathrm{R}$ \\
& & & glucopyranosyl & \\
D-Lactose & $\mathrm{i}$ & $-\mathrm{CH}_{2} \mathrm{OH}$ & $-\beta-\mathrm{D}-$ & $1^{\prime} \mathrm{S}, 2^{\prime} \mathrm{R}, 3^{\prime} \mathrm{R}, 4^{\prime} \mathrm{R}$
\end{tabular}

To provide unambiguous confirmation of the verdazyl structure, radical 3a was characterized by Xray crystallography. Crystals were grown by slow evaporation of a methanol solution. Full details, including data collection and refinement have been deposited in the Cambridge Crystallographic Data Centre (CCDC), deposition number 1475223. Radical 3a crystallizes in the monoclinic space group P112 (No. 4) with two independent molecules in the assymmetric unit. The two molecules differ only 
in slightly different conformations of the polyol side chain. A thermal ellipsoid plot is shown in figure 2. The polyol groups form a two dimensional hydrogen bonded network that separates layers containing verdazyl rings. Unlike other examples, the verdazyl ring does not participate in hydrogen bonding. The geometry of the verdazyls themselves is very similar to that observed for other 1,5-diisopropyl verdazyls.

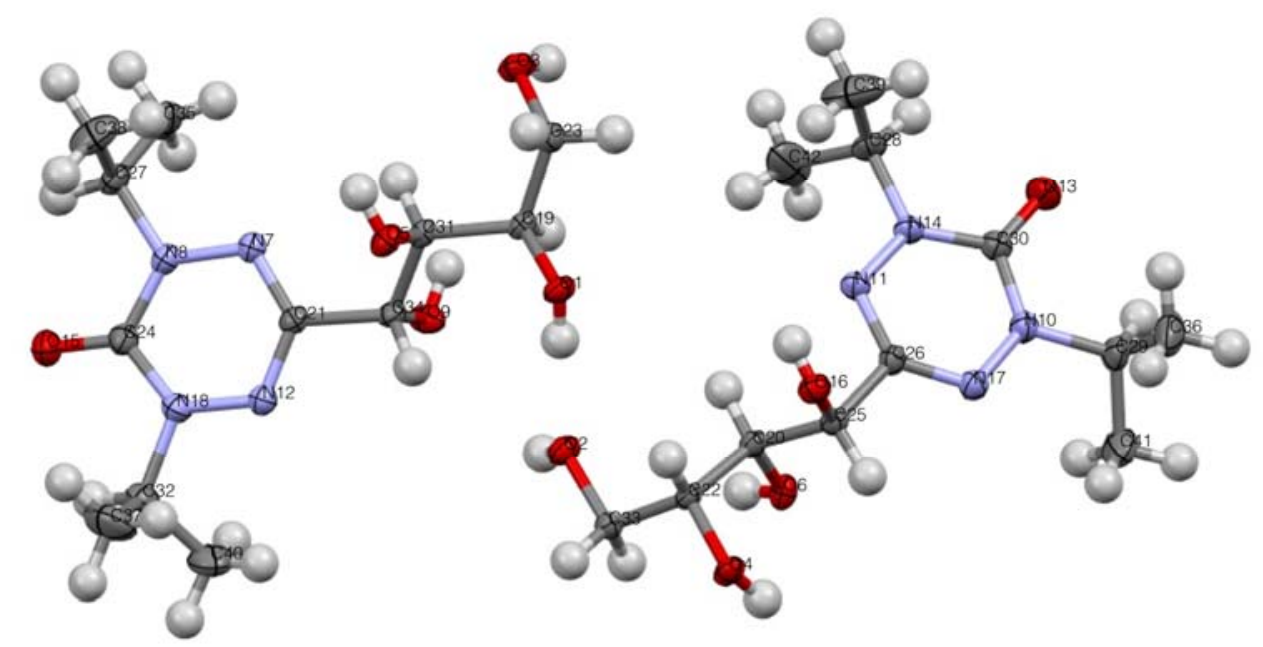

Figure 2 Thermal Ellipsoid plot of the two independent molecules of 3a in the unit cell. Ellipsoids are drawn at the $50 \%$ probability level.

All of the radicals gave ESR spectra characteristic of 1,5-diisopropyloxoverdazyls. ${ }^{28,}{ }^{34}$ Figure 3 shows the spectrum and simulation for 3d. Spectra and simulations for the remaining verdazyls are provided in supporting information while spectral parameters are reported in table 2 . There is very little variation in most of hyperfine parameters $(+/-0.1 \mathrm{G})$ between radicals; this is typical for such systems since the spin density is largely localized on the verdazyl nitrogens. The biggest variations are seen in coupling to the side chain hydrogen. These variations are probably due to small differences in preferred conformation. 




Figure 3. ESR spectrum (top) and simulation (bottom) of 3d in water. Simulation parameters for all new radicals are shown in Table 4. The remaining simulations and spectra are reported in supporting information.

Table 2. ESR parameters for 3a-i

$$
g \quad \text { linewidth } / \mathrm{G} \quad a_{\mathrm{N} 1,5} / \mathrm{G} \quad a_{\mathrm{N} 2,4} / \mathrm{G} \quad a_{\mathrm{H}}\left(\text { isopropyl) } a_{\mathrm{H}}\right. \text { (sidechain) }
$$

\begin{tabular}{ccccccc}
\hline 3a & 2.0033 & 0.53 & 5.4 & 6.6 & 0.97 & 1.2 \\
3b & 2.0022 & 0.43 & 5.4 & 6.6 & 0.97 & 1.34 \\
$\mathbf{3 c}$ & 2.0044 & 0.82 & 5.4 & 6.4 & 1.23 & 1.5 \\
$\mathbf{3 d}$ & 2.0047 & 1.1 & 5.5 & 6.5 & 1.2 & 1.6 \\
$\mathbf{3 e}$ & 2.0045 & 1.4 & 5.4 & 6.4 & 1.2 & 2.0 \\
$\mathbf{3 f}$ & 2.0045 & 1.2 & 5.4 & 6.3 & 1.3 & 2.1
\end{tabular}




$$
g \quad \text { linewidth } / \mathrm{G} \quad a_{\mathrm{N} 1,5} / \mathrm{G} \quad a_{\mathrm{N} 2,4} / \mathrm{G} \quad a_{\mathrm{H}}\left(\text { isopropyl) } a_{\mathrm{H}}\right. \text { (sidechain) }
$$

\begin{tabular}{rrrrrrr}
\hline $\mathbf{3 g}$ & 2.0056 & 1.4 & 5.6 & 6.4 & 1.3 & 2.5 \\
$\mathbf{3 h}$ & 2.0035 & 1.3 & 5.6 & 6.4 & 1.3 & 1.6 \\
$\mathbf{3 i}$ & 2.0034 & 1.1 & 5.6 & 6.5 & 1.3 & 2.2 \\
\hline
\end{tabular}

Electronic spectra were similar to the spectra we reported for 3-methyl-1,5,-diisopropyl-6oxoverdazyl $^{34}$ though there are differences in intensity and width of the contributing bands as a result of the change of solvent from hexane to methanol (Figure 4).

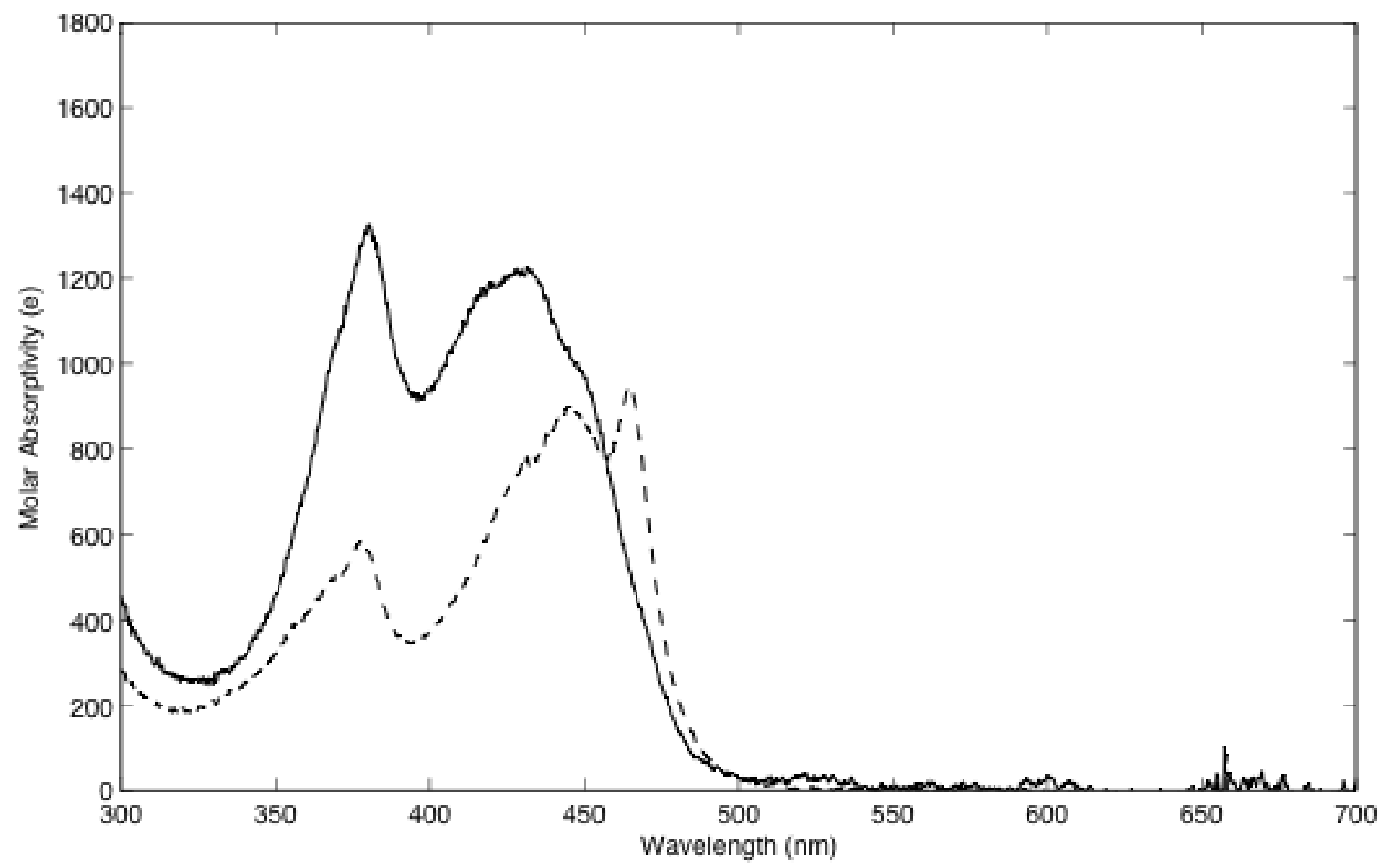

Figure 4. UV-vis spectrum of radical 3a in methanol (solid line) along with 3-methyl-1,5-diisopropyl-6oxoverdazyl in hexane (broken line).

All of the new verdazyls are quite soluble in water, but less soluble in less polar solvents. We estimated water solubility for the mannose derived verdazyl $3 \mathbf{f}$ of at least 0.7 mol. $\mathrm{L}^{-1}$ Solubility of the other verdazyls was comparably large. Electronic spectra were unaffected by variation in $\mathrm{pH}$ from 4-10 though slow decomposition occurred at $\mathrm{pH} 0$ (the UV-vis spectrum lost two thirds of its intensity over a 
$24 \mathrm{~h}$ period). Electronic spectra were also unaffected by addition of hydrogen peroxide or ascorbic acid at neutral $\mathrm{pH}$.

To gain an initial idea of the potential of these molecules as probes we examined their ability to quench the fluorescence of organic fluorophores. In methanol solution, only very weak quenching of the fluorescence of riboflavin was observed. Significantly greater quenching was observed when the solvent was changed to chloroform. (Figure 5). Quenching was also observed with pyrene in acetonitrile. SternVolmer plots are shown in figure 6.

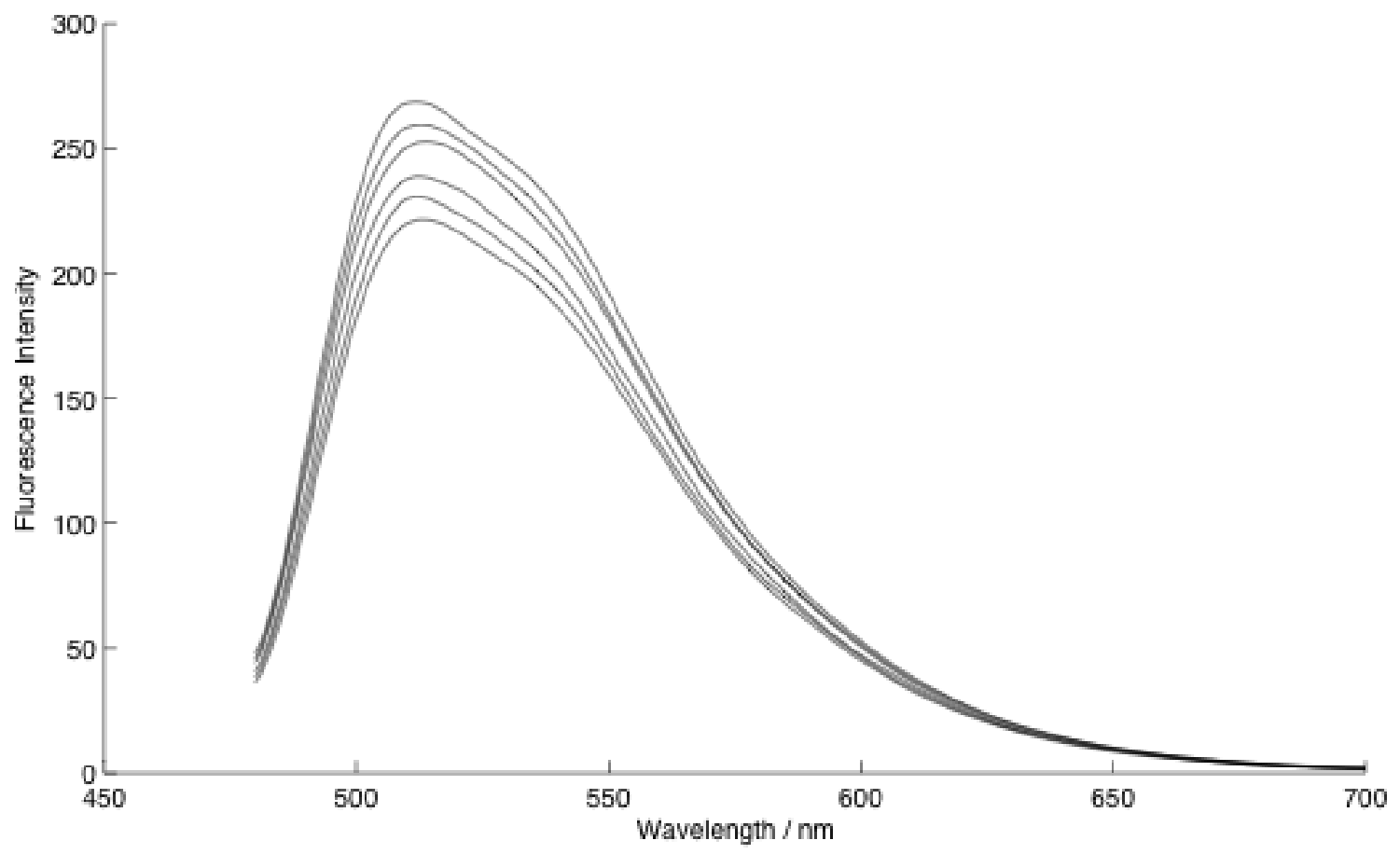

Figure 5. Fluorescence quenching of riboflavin with radical 3d in chloroform. Each line corresponds to an increase in verdazyl concentration of $0.0375 \mathrm{mM}$. 


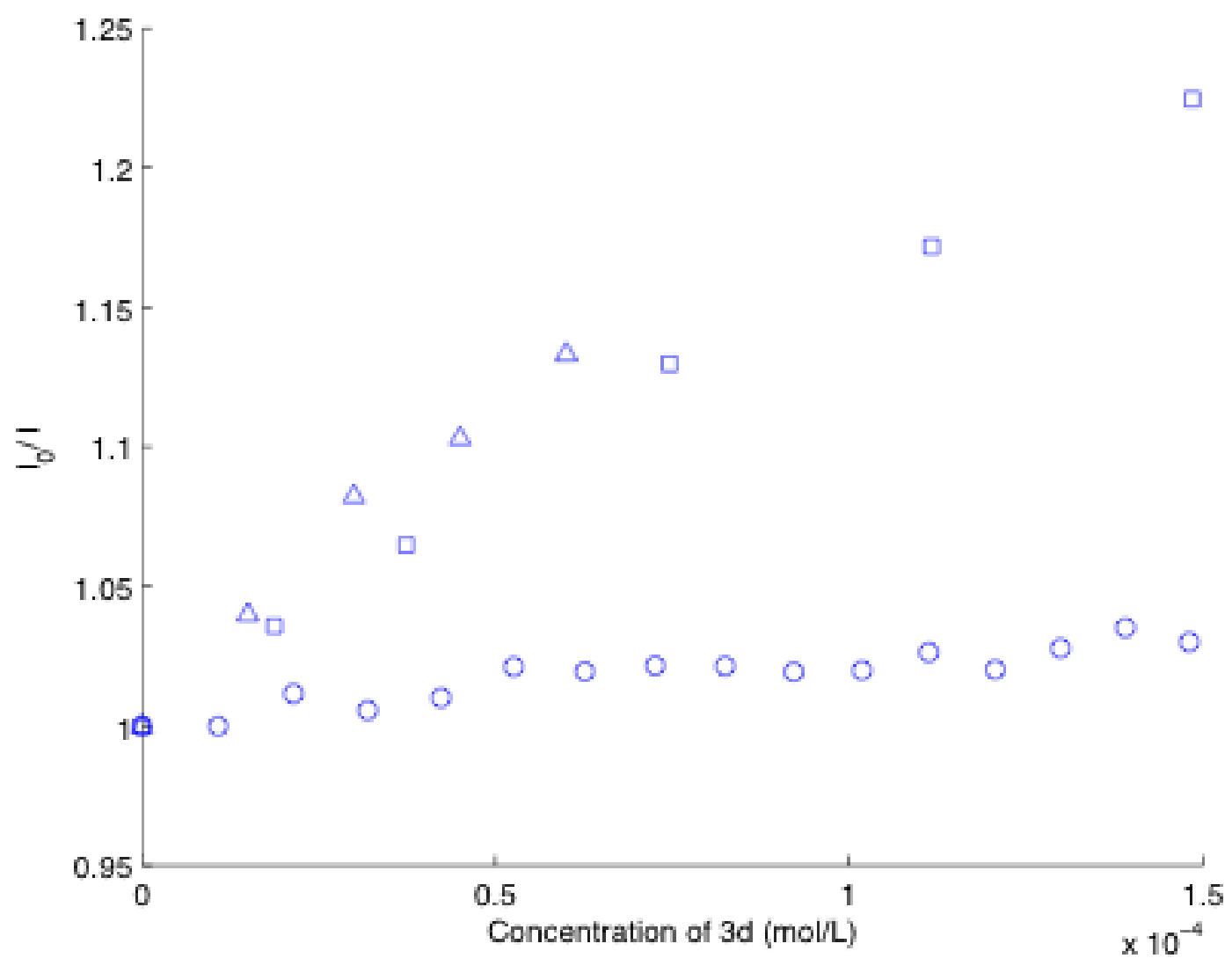

Figure 6. Stern-Vollmer plots for fluorescence quenching with radical 3d. Riboflavin $\left(\lambda_{e m}=510 \mathrm{~nm}\right)$ in methanol (circles), riboflavin in chloroform (squares), and pyrene $\left(\lambda_{e m}=393 \mathrm{~nm}\right)$ in acetonitrile (triangles)

\section{Discussion}

Most stable organic free radicals are essentially lipophilic species. Nitroxides, nitronyl nitroxides, verdazyls and others typically sport alkyl or aryl substituents that contribute to stability through delocalization or steric hindrance. Prior strategies for generating water soluble stable radicals have involved substitution with easily ionized species such as sulfonic acids or carboxylic acids. While this can give the required solubility it also introduces ionic groups that may not be desirable in some applications. For example carboxylates may result in $\mathrm{pH}$ sensitive solubility and metal ion coordination $^{27}$ and even more inert charged functional groups (such as sulfonates) may favor interactions with oppositely charged ions. Kuhn's early approach using aldoses is a promising 
alternative, but his verdazyls derived from formazans were less than ideal. The products are rather poorly characterized, and appear to be a mixture of verdazyl and leucoverdazyl. Furthermore, they underwent disproportionation to a leucoverdazyl and verdazylium ion below $\mathrm{pH} 7 .^{25}$ The 6oxoverdazyls, with more widely separated oxidation and reduction potentials, are less prone to disproportionation. ${ }^{35}$ Isopropyl groups in the 1 and 5 positions result in more tractable tetrazane intermediates as well as more stable free radicals. ${ }^{28}$ As a result, the combination of 2,4diisopropylcarbonobishydrazide and aldoses gives water soluble free radicals, in good to excellent yields under very mild reaction conditions. Most previous reports of spin labelled carbohydrates require extensive use of protecting groups to incorporate the radical. ${ }^{36}$ Use of monosaccharides disrupts the cyclic structure of the sugar, and thus we attempted the use of reducing disaccharides such as lactose or maltose to give spin labelled carbohydrates with an intact pyranose ring; unfortunately, purification of the disaccharide derived radicals proved challenging - purification and characterization of these species will be an ongoing project.

The potential range of application of these radicals is enhanced by the radical stability. Solid samples are stable for months in air at room temperature, and in aqueous solution are stable to mild reductants such as ascorbic acid, and oxidants such as hydrogen peroxide. This contrasts with nitroxides that are reduced relatively rapidly by ascorbic acid and have half lives of a few minutes in vivo. ${ }^{23-24}$ Furthermore we have detected no immediate sign of decomposition within a $\mathrm{pH}$ range of 4-10; at $\mathrm{pH} \sim 0$, slow decomposition was observed. By comparison, nitronyl nitroxides show immediate spectral changes at very low $\mathrm{pH}$, though the resulting protonated cation seems to decompose at a similar rate to the verdazyls under the same conditions. ${ }^{37-38}$

Fluorescence quenching by stable free radicals (typically nitroxides) is a well established phenomenon, but verdazyls may be complementary to existing quenchers, in part because of their stability to a variety of common reagents. Very little quenching of fluorescein, rhodamine B, coumarin 487 or riboflavin was observed in methanol solution at low quencher concentration $(\sim 0.1 \mathrm{mM})$, but as has been previously noted, ${ }^{39}$ observing significant quenching of short lifetime fluorophores, even if 
quenching occurs at diffusion controlled rates, requires relatively high concentrations of quencher (> $1 \mathrm{mM})$. At such concentrations absorption of the verdazyl itself provides an inner filter for the incident light, masking any loss of fluorescence due to quenching. ${ }^{39}$ Pyrene has a significantly longer fluorescence lifetime $\mathrm{e}^{40}$ than the other dyes used $\mathrm{d}^{41}(\sim 200 \mathrm{~ns} \mathrm{vs} \sim 5 \mathrm{~s})$ and thus quenching was more easily observed. In any-case efficient quenching with unbound quencher is counterproductive in attempting to use quenching as a probe of a specific intermolecular reaction. More promising is the observation of quenching of riboflavin fluorescence in chloroform. Both the verdazyls 3a-h, and riboflavin (figure 7) have numerous hydrogen bonding sites.

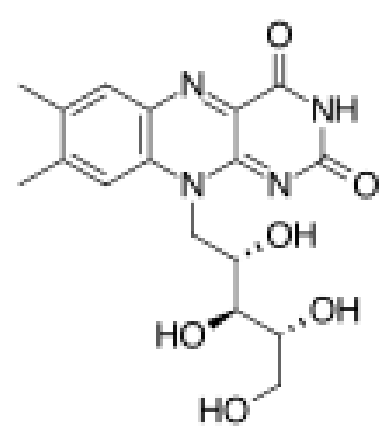

Figure 7. Structure of riboflavin

The lack of hydrogen bonding with the chloroform solvent favors hydrogen bonding interactions between fluorophore and quencher and facilitates quenching. Proposed quenching mechanisms for free radicals are varied but in many cases the most prevalent mechanism seems to be enhanced intersystem crossing. ${ }^{42}$ Further study will be required before any conclusion can be made regarding quenching by verdazyls; in any case the differences in stability between verdazyls and other stable radicals may well be of utility in designing new, selective profluorescent radicals.

\subsection{Conclusion}

We have synthesized a series of water soluble radicals derived from sugars. These radicals are stable in aqueous solutions over a wide range of $\mathrm{pH}$ and can quench the fluorescence of organic dyes, though the full scope of quenching is still under investigation. They complement the array of existing radical spin probes and radical fluorescence quenchers and thus expand the applicability of these tools to new areas. Furthermore, the ability to introduce a stable free radical under very mild aqueous conditions, 
suggests the possibility of direct introduction of verdazyl spin labels to more complex biomolecules. We hope to report on such studies in the near future.

\section{Experimental}

\subsection{General}

NMR spectra were recorded on a Varian Mercury $300 \mathrm{MHz}$ spectrometer. Solvent signals were used to determine chemical shift relative to TMS. Coupling constants are reported in Hz. Purity of the verdazyls was assessed with HPLC on a $15 \mathrm{~cm} \mathrm{C18}$ reverse phase column eluting isocratically with $20 \%$ methanol in water. Specific rotations were measured in methanol. Absolute configuration was assigned based upon the starting sugar. Since no diastereomers were observed by either HPLC or NMR we are

confident that the absolute configuration did not change during reaction. 2,4diisopropylcarbonohydrazide bis-hydrochloride was synthesized using literature procedures. ${ }^{28}$

\subsection{General Procedure for Tetrazanes}

2,4-diisopropylcarbonohydrazide bis-hydrochloride $(2 \mathrm{mmol})$ and the aldose $(2 \mathrm{mmol})$ were dissolved in a minimum amount of water. To this solution was added $4 \mathrm{mmol}$ of sodium acetate dissolved in water. The solution was stirred at room temperature for 4 to $6 \mathrm{~h}$. After this period, the mixture was extracted four times with an equal volume of 1-butanol. The combined butanol layers were dried with sodium sulfate, filtered and evaporated to give the crude yellow aldose-tetrazane. The crude compound was washed with hot hexane or heptane to leave an off-white aldose-tetrazane.

\subsection{General Procedure for Verdazyls}

An aldose-tetrazane (2) (0.5 mmol) was dissolved in minimum amount of water. Potassium ferricyanide $\left(1.5 \mathrm{mmol}\right.$ ) was combined with 10 drops of $2 \mathrm{M} \mathrm{Na}_{2} \mathrm{CO}_{3}$ (aq) and dissolved in $2 \mathrm{~mL}$ of water. The two solutions were combined and stirred slowly whereupon the mixture gave a vigorous effervescence and turned yellow. After effervescence stopped, the solution was extracted four times with with 1-butanol, the organic layer dried with sodium sulfate, filtered, and evaporated to give the aldose- verdazyl. Purity of the verdazyls was assessed with HPLC on a $15 \mathrm{~cm}$ C18 reverse phase column eluting isocratically with $20 \%$ methanol in water. 


\subsection{Quenching experiments}

Aliquots of a solution of radical 3d were added to solutions of fluorescent dyes and the fluorescence intensity recorded at room temperature as a function of quencher concentration. Dye solutions were sufficiently dilute that the absorbance maximum was less than 0.1 to minimize inner filter effects. UVvis spectra of the solutions were recorded again at the end of the experiment to confirm that any loss of fluorescence was not due to inner filter effects from the quencher.

\subsection{1'S, 2'S, 3'R-2,4-Diisopropyl-6-(1',2',3',4'-tetrahydroxybutyl)-1,2,4,5-tetrazane-3-one(2a)}

Following the general procedure above, D-Lyxose $(0.302 \mathrm{~g}, 2.01 \mathrm{mmol})$ gave $0.595 \mathrm{~g} \mathrm{2a}(97 \%)$ with mp 109-114 ${ }^{\circ} \mathrm{C} ;{ }^{1} \mathrm{H}-\mathrm{NMR}\left(300 \mathrm{MHz} ; \mathrm{CD}_{3} \mathrm{OD}\right.$ ): 4.53 (septet, $J=6.7 \mathrm{~Hz}, 1 \mathrm{H}$ ), 4.51 (septet, $J=6.6 \mathrm{~Hz}, 1 \mathrm{H}$ ), 3.95-3.87 (m, 2H), $3.73(\mathrm{dd}, J=9.4,1.3 \mathrm{~Hz}, 1 \mathrm{H}), 3.65(\mathrm{~d}, J=6.4 \mathrm{~Hz}, 3 \mathrm{H}), 1.13(\mathrm{~d}, J=6.7 \mathrm{~Hz}, 1 \mathrm{H}), 1.12(\mathrm{~d}$, $J=6.6 \mathrm{~Hz}, 1 \mathrm{H}), 1.08(\mathrm{~d}, J=6.4 \mathrm{~Hz}, 1 \mathrm{H}), 1.07(\mathrm{~d}, J=6.4 \mathrm{~Hz}, 1 \mathrm{H}) ;{ }^{13} \mathrm{CNMR} 17.6\left(\mathrm{CH}_{3}\right), 17.7\left(\mathrm{CH}_{3}\right), 18.5$ $\left(\mathrm{CH}_{3}\right), 18.6\left(\mathrm{CH}_{3}\right), 47.8$ (isopropyl $\left.\mathrm{CH}\right), 48.0$ (isopropyl $\left.\mathrm{CH}\right), 63.6\left(\mathrm{CH}_{2}\right), 68.8(\mathrm{CH}), 69.2(\mathrm{Cl}), 70.3$ (C3), $70.5(\mathrm{C} 2), 154.91(\mathrm{C}=\mathrm{O})$. HRMS calcd for $\mathrm{C}_{12} \mathrm{H}_{27} \mathrm{~N}_{4} \mathrm{O}_{5}\left(\mathrm{MH}^{+}\right)$307.1981, found 307.1969; IR (ATR) $1576(\mathrm{C}=\mathrm{O}), 3230,3346 \mathrm{~cm}^{-1}(\mathrm{~N}-\mathrm{H} / \mathrm{O}-\mathrm{H})$.

\subsection{1'R, 2'S, 3'R-2,4-Diisopropyl-6-(1',2',3',4'- tetrahydroxybutyl)-1,2,4,5-tetrazane-3-one (2b)}

Following the general procedure above, D-Xylose $(0.301 \mathrm{~g}, 0.201 \mathrm{mmol})$ gave $0.402 \mathrm{~g} \mathbf{2 b}(65 \%)$ with mp 143-146 ${ }^{\circ} \mathrm{C} ;{ }^{1} \mathrm{H}-\mathrm{NMR}\left(300 \mathrm{MHz} ; \mathrm{CD}_{3} \mathrm{OD}\right.$ ): $\delta 4.52$ (septet, $J=6.5 \mathrm{~Hz}, 2 \mathrm{H}$ ), 3.97 (dd, $J=5.9,3.3 \mathrm{~Hz}$, 1H), 3.83-3.75 (m, 2H), $3.66(\mathrm{~m}, 2 \mathrm{H}), 3.54(\mathrm{~d}, J=2.8 \mathrm{~Hz}, 1 \mathrm{H}), 1.12(\mathrm{~d}, J=6.6 \mathrm{~Hz}, 1 \mathrm{H}), 1.07(\mathrm{~d}, J=6.6$ $\mathrm{Hz}, 1 \mathrm{H}) ;{ }^{13} \mathrm{C}$ NMR (75 MHz; $\left.\mathrm{CD}_{3} \mathrm{OD}\right): \delta 154.5,71.6,70.5,69.0,63.4,47.7,18.7,18.2,17.8$; HRMS calcd for $\mathrm{C}_{12} \mathrm{H}_{27} \mathrm{~N}_{4} \mathrm{O}_{5}\left(\mathrm{MH}^{+}\right)$307.1981, found 307.1864; IR (ATR) $1577(\mathrm{C}=\mathrm{O}), 3384,3442 \mathrm{~cm}^{-1}(\mathrm{~N}-$ $\mathrm{H} / \mathrm{O}-\mathrm{H})$

\subsection{1'S, 2'R, 3'R-2,4-Diisopropyl-6-(1',2',3',4'- tetrahydroxybutyl)-1,2,4,5-tetrazane-3-one (2c)}

Following the general procedure above, D-Ribose $(0.303 \mathrm{~g}, 2.20 \mathrm{mmol})$ gave $0.606 \mathrm{~g} 2 \mathrm{c}(98 \%)$ with mp 113-118 ${ }^{\circ} \mathrm{C} ;{ }^{1} \mathrm{H}-\mathrm{NMR}\left(300 \mathrm{MHz} ; \mathrm{CD}_{3} \mathrm{OD}\right): \delta$ 4.61-4.47 (m, 3H), $3.94(\mathrm{dd}, J=7.8,1.7 \mathrm{~Hz}, 1 \mathrm{H})$, 3.83-3.76 (m, 3H), 3.69-3.61 (m, 2H), $1.13(\mathrm{~d}, J=6.8 \mathrm{~Hz}, 6 \mathrm{H}), 1.09-1.06(\mathrm{~m}, J=6.5,2.4 \mathrm{~Hz}, 6 \mathrm{H}) ;{ }^{13} \mathrm{C}$ 
NMR (75 MHz; $\left.\mathrm{CD}_{3} \mathrm{OD}\right): \delta 154.7,73.8,71.9,71.1,68.9,62.9,47.94,47.78,18.64,18.53,17.70,17.69$;

HRMS calcd for $\mathrm{C}_{12} \mathrm{H}_{27} \mathrm{~N}_{4} \mathrm{O}_{5}\left(\mathrm{MH}^{+}\right)$307.1981, found 307.1891; IR (ATR) $1567(\mathrm{C}=\mathrm{O}), 3240,3346 \mathrm{~cm}^{-}$

${ }^{1}(\mathrm{~N}-\mathrm{H} / \mathrm{O}-\mathrm{H})$

\section{$4.81^{\prime} R, 2^{\prime} R, 3^{\prime} R-2,4-D i i s o p r o p y l-6-(1 ', 2 ', 3 ', 4$ '-tetrahydroxybutyl)-1,2,4,5-tetrazane-3-one(2d)}

Following the general procedure above, D-Arabinose $(0.305 \mathrm{~g} 2.03 \mathrm{mmol})$ gave $0.589 \mathrm{~g} \mathrm{2d}(95 \%)$ with mp 136-139 ${ }^{\circ} \mathrm{C} ;{ }^{1} \mathrm{H}-\mathrm{NMR}\left(300 \mathrm{MHz} ; \mathrm{CD}_{3} \mathrm{OD}\right): \delta 4.59-4.43(\mathrm{~m}, 2 \mathrm{H}), 3.99(\mathrm{~d}, J=2.2 \mathrm{~Hz}, 1 \mathrm{H}), 3.82-$ $3.56(\mathrm{~m}, 6 \mathrm{H}), 1.14-1.06(\mathrm{~m}, 12 \mathrm{H}) ;{ }^{13} \mathrm{C} \mathrm{NMR}\left(75 \mathrm{MHz} ; \mathrm{CD}_{3} \mathrm{OD}\right): \delta 154.7,72.1,71.5,70.7,68.4,63.5$, 47.8, 47.7, 18.8, 18.7, 18.0, 17.8; HRMS calcd for $\mathrm{C}_{12} \mathrm{H}_{27} \mathrm{~N}_{4} \mathrm{O}_{5}\left(\mathrm{MH}^{+}\right)$307.1981, found 307.1986; IR (ATR) $1577(\mathrm{C}=\mathrm{O}), 3212,3327,3365,3433 \mathrm{~cm}^{-1}(\mathrm{~N}-\mathrm{H} / \mathrm{O}-\mathrm{H})$

4.9 1'R, 2'S, 3'R, 4'R-2,4-Diisopropyl-6-(1',2',3',4',5'- pentahydroxypentyl)-1,2,4,5-tetrazane-3one(2e)

Following the general procedure above D-Glucose $(0.330 \mathrm{~g} .1 .83 \mathrm{mmol})$ gave $0.617 \mathrm{~g} \mathrm{2e}(98 \%)$ as a glassy solid with ${ }^{1} \mathrm{H}-\mathrm{NMR}\left(300 \mathrm{MHz} ; \mathrm{CD}_{3} \mathrm{OD}\right): \delta$ 4.58-4.45 (m, 2H), 4.06-3.95 (m, 2H), 3.82-3.71 (m, 2H), 3.65-3.58 (m, 2H), $3.52(\mathrm{~d}, J=2.3 \mathrm{~Hz}, 1 \mathrm{H}), 1.14-1.07(\mathrm{~m}, 12 \mathrm{H}) ;{ }^{13} \mathrm{C}$ NMR $\left(75 \mathrm{MHz}\right.$; $\left.\mathrm{CD}_{3} \mathrm{OD}\right): \delta$ 154.5, 71.8, 71.0, 70.8, 68.7, 63.8, 63.1, 47.85, 47.74, 18.5, 18.1, 17.7; HRMS calcd for $\mathrm{C}_{13} \mathrm{H}_{29} \mathrm{~N}_{4} \mathrm{O}_{5}$ $\left(\mathrm{MH}^{+}\right)$337.2086, found 337.1990; IR (ATR) $1577(\mathrm{C}=\mathrm{O}), 3269,3308,3384 \mathrm{~cm}^{-1}(\mathrm{~N}-\mathrm{H} / \mathrm{O}-\mathrm{H})$

\subsection{1'S, 2'S, 3'R, 4'R-2,4-Diisopropyl-6-(1',2',3',4',5'-pentahydroxypentyl)-1,2,4,5-tetrazane-3-} one(2f)

Following the general procedure above D-Mannose $(0.360 \mathrm{~g} 2.0 \mathrm{mmol})$ gave $0.652 \mathrm{~g} \mathbf{2 f}(97 \%)$ as a glassy solid with ${ }^{1} \mathrm{H}-\mathrm{NMR}\left(300 \mathrm{MHz}\right.$; $\left.\mathrm{CD}_{3} \mathrm{OD}\right): \delta 4.59-4.44(\mathrm{~m}, 2 \mathrm{H}), 4.00(\mathrm{~d}, J=9.5 \mathrm{~Hz}, 1 \mathrm{H}), 3.93$ (dd, $J=9.5,1.3 \mathrm{~Hz}, 1 \mathrm{H}), 3.88-3.62(\mathrm{~m}, 5 \mathrm{H}), 1.21-0.98(\mathrm{~m}, 12 \mathrm{H}) ;{ }^{13} \mathrm{C} \mathrm{NMR}\left(75 \mathrm{MHz} ; \mathrm{CD}_{3} \mathrm{OD}\right): \delta 154.9$, 71.6, 69.74, 69.65, 69.1, 68.9, $64.0\left(\mathrm{CH}_{2}\right), 48.1,47.8,18.68,18.60,17.72,17.66$; HRMS calcd for $\mathrm{C}_{13} \mathrm{H}_{29} \mathrm{~N}_{4} \mathrm{O}_{5}\left(\mathrm{MH}^{+}\right)$337.2086, found 337.2084; IR (ATR) $1596(\mathrm{C}=\mathrm{O}), 3240,3269,3365 \mathrm{~cm}^{-1}(\mathrm{~N}-\mathrm{H} / \mathrm{O}-$ H) 


\subsection{1'R, 2'S, 3'S, 4'R-2,4-Diisopropyl-6-(1',2',3',4',5'-pentahydroxypentyl)-1,2,4,5-tetrazane-3-}

one(2g)

Following the general procedure above D-Galactose $(0.311 \mathrm{~g}, 1.77 \mathrm{mmol})$ gave $0.494 \mathrm{~g} \mathbf{2 g}(85 \%)$ with mp $127-133{ }^{\circ} \mathrm{C}(\mathrm{dec}){ }^{1} \mathrm{H}-\mathrm{NMR}\left(300 \mathrm{MHz} ; \mathrm{CD}_{3} \mathrm{OD}\right): \delta 4.59-4.48$ (m, 2H), 4.03 (dd, J=4.5, $1.9 \mathrm{~Hz}$, 1H), 3.93-3.88 (m, 2H), 3.69 (d, J=9.0 Hz, 1H), 3.65 (d, J=6.3 Hz, 2H), 3.58 (d, J=4.6 Hz, $1 \mathrm{H}), 3.31$ (d, $J=1.6 \mathrm{~Hz}, 1 \mathrm{H}), 1.24-1.08(\mathrm{~m}, 12 \mathrm{H}) ;{ }^{13} \mathrm{C} \mathrm{NMR}\left(75 \mathrm{MHz} ; \mathrm{CD}_{3} \mathrm{OD}\right): \delta 154.7,71.19,71.09,70.5,69.9$, 68.3, 63.7, 47.75, 47.67, 18.63, 18.59, 17.84, 17.70; HRMS calcd for $\mathrm{C}_{13} \mathrm{H}_{29} \mathrm{~N}_{4} \mathrm{O}_{5}\left(\mathrm{MH}^{+}\right)$337.2086, found 337.2084; IR (ATR) $1577(\mathrm{C}=\mathrm{O}), 3250,3346,3423 \mathrm{~cm}^{-1}(\mathrm{~N}-\mathrm{H} / \mathrm{O}-\mathrm{H})$

\subsection{1'R, 2'S, 3'R, 4'R-2,4-Diisopropyl-6-(3'- $\alpha-D$-glucopyranosyl-1',2',4',5'-} tetrahydroxypentyl)-1,2,4,5-tetrazane-3-one(2h)

Following the general procedure above D-Maltose $(0.684 \mathrm{~g}, 2 \mathrm{mmol})$ gave $0.767 \mathrm{~g} \mathbf{2 h}(1.5 \mathrm{mmol}$, $75 \%)$ as a glassy solid with ${ }^{1} \mathrm{H}-\mathrm{NMR}\left(300 \mathrm{MHz} ; \mathrm{D}_{2} \mathrm{O}\right): \delta 0.89(\mathrm{~m}, 12 \mathrm{H}), 3.2(\mathrm{~m}, 1 \mathrm{H}), 3.3-3.8(\mathrm{~m} 11 \mathrm{H})$, $4.0(\mathrm{~m}, 1 \mathrm{H}), 4.24(\mathrm{~m}, 2 \mathrm{H}), 4.87(\mathrm{~m}, 1 \mathrm{H}) ;{ }^{13} \mathrm{C} \mathrm{NMR}\left(75 \mathrm{MHz} ; \mathrm{D}_{2} \mathrm{O}\right): \delta 154.8,100.6,81.3,73.0,72.9$, $72.5,71.7,70.9,69.5,69.1,68.5,62.6,60.5,48.0,47.9,18.9,18.8,18.4,18.3$; IR (ATR) $3310(\mathrm{O}-\mathrm{H})$ $1505 \mathrm{~cm}^{-1}(\mathrm{C}=\mathrm{O})$; HRMS calcd for $\mathrm{C}_{19} \mathrm{H}_{39} \mathrm{~N}_{4} \mathrm{O}_{11}\left(\mathrm{MH}^{+}\right)$499.2610, found 499.2610.

4.13 1'R, 2'S, 3'R, 4'R-2,4-Diisopropyl-6-(3'-a-D-galactopyranosyl-1',2',4',5'tetrahydroxypentyl)-1,2,4,5-tetrazane-3-one(2i)

Following the general procedure above D-Lactose $(0.684 \mathrm{~g}, 2 \mathrm{mmol})$ gave $0.830 \mathrm{~g} \mathbf{2 i}(83 \%)$ as a glassy solid with ${ }^{1} \mathrm{H}-\mathrm{NMR}\left(300 \mathrm{MHz} ; \mathrm{D}_{2} \mathrm{O}\right): \delta 0.9(\mathrm{~m}, 12 \mathrm{H}), 3.4-4.0(\mathrm{~m}, 13 \mathrm{H}), 4.2(\mathrm{~m}, 3 \mathrm{H}) ;{ }^{13} \mathrm{C}$ NMR $\left(75 \mathrm{MHz} ; \mathrm{D}_{2} \mathrm{O}\right): \delta 157.1,104.8,80.0,77.4,75.2,74.0,73.8,73.0,72.2,70.9,70.6,64.8,63.1,50.7$, 21.4, 21.33, 21.28, 20.9; IR (ATR) $3300(\mathrm{O}-\mathrm{H}), 1500 \mathrm{~cm}^{-1}(\mathrm{C}=\mathrm{O})$; HRMS calcd for $\mathrm{C}_{19} \mathrm{H}_{39} \mathrm{~N}_{4} \mathrm{O}_{11}\left(\mathrm{MH}^{+}\right)$ 499.2610, found 499.2609.

4.14 1'S, 2'S, 3'R-1,5-Diisopropyl-3-(1',2',3',4'- tetrahydroxybutyl)-6-oxoverdazyl (3a) 
Following the general procedure for verdazyls above, 2a $(0.43 \mathrm{~g}, 1.4 \mathrm{mmol})$ gave $\mathbf{3 a}$ as a yellow crystalline solid, (0.353 g 83\%) with mp 108-110 ${ }^{\circ} \mathrm{C}$; HRMS calcd for $\mathrm{C}_{12} \mathrm{H}_{24} \mathrm{~N}_{4} \mathrm{O}_{5}\left(\mathrm{MH}^{+}\right)$304.1747, found 304.1741; IR (ATR) $1692(\mathrm{C}=\mathrm{O}), 3240 \mathrm{~cm}^{-1}(\mathrm{O}-\mathrm{H})$; UV-vis $\left(\mathrm{CH}_{3} \mathrm{OH}\right) \lambda / \mathrm{nm},\left(\varepsilon / \mathrm{L} \mathrm{mol}^{-1} \mathrm{~cm}^{-1}\right)$ $380(1330), 431(1220) .[\alpha]_{D}=-12.0^{\circ}$; HPLC: product eluted at $11.16 \mathrm{~min}, 99 \%$ pure by integration.

\subsection{1'R, 2'S, 3'R-1,5-Diisopropyl-3-(1',2',3',4'- tetrahydroxybutyl)-6-oxoverdazyl (3b)}

Following the general procedure for verdazyls above, $\mathbf{2 b}(0.491 \mathrm{~g}, 1.6 \mathrm{mmol})$ gave $\mathbf{3 b}$ as a yellow crystalline solid $(0.453 \mathrm{~g}, 93 \%)$ with mp $113-118{ }^{\circ} \mathrm{C}$; HRMS calcd for $\mathrm{C}_{12} \mathrm{H}_{24} \mathrm{~N}_{4} \mathrm{O}_{5}\left(\mathrm{MH}^{+}\right)$304.1747, found 304.1713; IR (ATR) 1635, $1674(\mathrm{C}=\mathrm{O}), 3408 \mathrm{~cm}^{-1}(\mathrm{O}-\mathrm{H})$; UV-vis $\left(\mathrm{CH}_{3} \mathrm{OH}\right) \lambda / \mathrm{nm},\left(\varepsilon / \mathrm{L} \mathrm{mol}^{-1}\right.$ $\left.\mathrm{cm}^{-1}\right) 384(1600), 417(1280) .[\alpha]_{D}=+11.1^{\circ}$; HPLC: product eluted at $13.6 \mathrm{~min}, 90 \%$ pure by integration

\subsection{1'S, 2'R, 3'R-1,5-Diisopropyl-3-(1',2',3',4'- tetrahydroxybutyl)-6-oxoverdazyl (3c)}

Following the general procedure for verdazyls above, $2 \mathrm{c}(0.402 \mathrm{~g}, 1.3 \mathrm{mmol})$ gave $3 \mathrm{c}$ as a yellow crystalline solid $(0.374 \mathrm{~g}, 94 \%)$ with $\mathrm{mp} 124-125{ }^{\circ} \mathrm{C}$; HRMS calcd for $\mathrm{C}_{12} \mathrm{H}_{24} \mathrm{~N}_{4} \mathrm{O}_{5}\left(\mathrm{MH}^{+}\right)$304.1747, found 304.1739; IR (ATR) $1673(\mathrm{C}=\mathrm{O}), 3308,3404 \mathrm{~cm}^{-1}(\mathrm{O}-\mathrm{H})$; UV-vis $\left(\mathrm{CH}_{3} \mathrm{OH}\right) \lambda / \mathrm{nm},\left(\varepsilon / \mathrm{L} \mathrm{mol}^{-1}\right.$ $\left.\mathrm{cm}^{-1}\right) 380(1255), 431(1390) ;[\alpha]_{D}=-27.5$; HPLC: product eluted at $15.0 \mathrm{~min}, 98 \%$ pure by integration

\subsection{1'R, 2'R, 3'R-1,5-Diisopropyl-3-(1',2',3',4'-tetrahydroxybutyl)-6-oxoverdazyl(3d)}

Following the general procedure for verdazyls above, $2 \mathbf{d}(0.401 \mathrm{~g}, 1.31 \mathrm{mmol})$ gave $\mathbf{3 d}$ as a yellow crystalline solid (0.345g 87\%) with mp 173-174 ${ }^{\circ} \mathrm{C}$; HRMS calcd for $\mathrm{C}_{12} \mathrm{H}_{24} \mathrm{~N}_{4} \mathrm{O}_{5}\left(\mathrm{M}^{+}\right) 304.1747$, found 304.1737; IR (ATR) $1673(\mathrm{C}=\mathrm{O}), 3289 \mathrm{~cm}^{-1}(\mathrm{O}-\mathrm{H})$; UV-vis $\left(\mathrm{CH}_{3} \mathrm{OH}\right) \lambda / \mathrm{nm},\left(\varepsilon / \mathrm{L} \mathrm{mol}^{-1} \mathrm{~cm}^{-1}\right) 380$ (1170), $430(1080) ;[\alpha]_{D}=+7.3$; HPLC: product eluted at $11.86 \mathrm{~min}, 92 \%$ pure by integration

\subsection{1'R, 2'S, 3'R, 4'R-1,5-Diisopropyl-6-(1',2',3',4',5'- pentahydroxypentyl)-6-oxoverdazyl (3e)}

Following the general procedure for verdazyls above, $\mathbf{2 e}(0.632 \mathrm{~g}, 1.88 \mathrm{mmol})$ gave $\mathbf{3 e}$ as a yellow crystalline solid $(0.517 \mathrm{~g}, 82 \%)$ with m.p. 102-105 ${ }^{\circ} \mathrm{C}$; HRMS calcd for $\left(\mathrm{C}_{13} \mathrm{H}_{26} \mathrm{~N}_{4} \mathrm{O}_{6}\right)_{2} \mathrm{Na}^{+}\left(\mathrm{M}_{2} \mathrm{Na}^{+}\right)$ 689.3444, found 689.3448; IR (ATR) $1692(\mathrm{C}=\mathrm{O}), 3269 \mathrm{~cm}^{-1}(\mathrm{O}-\mathrm{H}) ; \mathrm{UV}$-vis $\left(\mathrm{CH}_{3} \mathrm{OH}\right) \lambda / \mathrm{nm},(\varepsilon / \mathrm{L}$ 
$\left.\mathrm{mol}^{-1} \mathrm{~cm}^{-1}\right) 380(1500), 431(1350) ;[\alpha]_{\mathrm{D}}=+0.5$; HPLC: product eluted at 9.7 min, 90\% pure by integration

\subsection{1'S, 2'S, 3'R, 4'R-1,5-Diisopropyl-6-(1',2',3',4',5'-pentahydroxypentyl)-6-oxoverdazyl (3f)}

Following the general procedure for verdazyls above, $\mathbf{2 f}(0.652 \mathrm{~g}, 1.94 \mathrm{mmol})$ gave $\mathbf{3 f}(0.429 \mathrm{~g}, 66 \%)$ with mp 67-77 ${ }^{\circ} \mathrm{C}$; HRMS calcd for $\mathrm{C}_{13} \mathrm{H}_{26} \mathrm{~N}_{4} \mathrm{O}_{6}\left(\mathrm{MH}^{+}\right)$334.1852, found 334.1843; IR (ATR) 1674 $(\mathrm{C}=\mathrm{O}), 3307 \mathrm{~cm}^{-1}(\mathrm{O}-\mathrm{H}) ; \mathrm{UV}$-vis $\left(\mathrm{CH}_{3} \mathrm{OH}\right) \lambda / \mathrm{nm},\left(\varepsilon / \mathrm{L} \mathrm{mol}^{-1} \mathrm{~cm}^{-1}\right) 380(1380), 430(1290) ;[\alpha]_{\mathrm{D}}=-$ 20.0; HPLC: product eluted at $9.55 \mathrm{~min}, 99 \%$ pure by integration

\subsection{1'R, 2'S, 3'S, 4'R-1,5-Diisopropyl-6-(1',2',3',4',5'- pentahydroxypentyl)-6-oxoverdazyl (3g)}

Following the general procedure for verdazyls above, $\mathbf{2 g}(0.494 \mathrm{~g}, 1.5 \mathrm{mmol})$ gave $\mathbf{3 g}$ as a yellow glassy solid (0.444 g, 91\%) with mp 182-184 ${ }^{\circ} \mathrm{C}$; HRMS calcd for $\mathrm{C}_{13} \mathrm{H}_{26} \mathrm{~N}_{4} \mathrm{O}_{6}\left(\mathrm{MH}^{+}\right)$334.1852, found 334.1844; IR (ATR) $1674(\mathrm{C}=\mathrm{O}), 3327 \mathrm{~cm}^{-1}(\mathrm{O}-\mathrm{H})$; UV-vis $\left(\mathrm{CH}_{3} \mathrm{OH}\right) \lambda / \mathrm{nm},\left(\varepsilon / \mathrm{L} \mathrm{mol}^{-1} \mathrm{~cm}^{-1}\right) 380$ (1220), $430(1400) ;[\alpha]_{D}=-9.5 ;$ HPLC: product eluted at $12.7 \mathrm{~min}, 97 \%$ pure by integration

\subsection{1'R, 2'S, 3'R, 4'R-2,4-Diisopropyl-6-(3'- 2 -D-glucopyranosyl-1',2',4',5'-}

\section{tetrahydroxypentyl)-6-oxoverdazyl (3h)}

Following the general procedure for verdazyls above, $\mathbf{2 h}(0.1 \mathrm{~g}, 0.2 \mathrm{mmol})$ gave $\mathbf{3 h}$ as a yellow glassy solid (0.029 g, 29\%) with HRMS calcd for $\mathrm{C}_{19} \mathrm{H}_{36} \mathrm{~N}_{4} \mathrm{O}_{11}\left(\mathrm{MH}^{+}\right)$496.2375, found 496.2375; IR (ATR) $1642(\mathrm{C}=\mathrm{O}), 3329 \mathrm{~cm}^{-1}(\mathrm{O}-\mathrm{H})$; UV-vis $\left(\mathrm{CH}_{3} \mathrm{OH}\right) \lambda / \mathrm{nm},\left(\varepsilon / \mathrm{L} \mathrm{mol}^{-1} \mathrm{~cm}^{-1}\right) 383(830), 422$ (644); $[\alpha]_{\mathrm{D}}=+69.4^{\circ}$; HPLC: product eluted at $8.8 \mathrm{~min}$, approximately $70 \%$ pure by integration.

\subsection{1'R, 2'S, 3'R, 4'R-2,4-Diisopropyl-6-(3'-a-D-galactopyranosyl-1',2',4',5'-}

\section{tetrahydroxypentyl)-6-oxoverdazyl (3i)}

Following the general procedure for verdazyls above, $\mathbf{2} \mathbf{i}(0.1 \mathrm{~g}, 2 \mathrm{mmol})$ gave $\mathbf{3 i}$ as a yellow glassy solid (0.035 g, 35\%) with HRMS calcd for $\mathrm{C}_{19} \mathrm{H}_{36} \mathrm{~N}_{4} \mathrm{O}_{11}\left(\mathrm{MH}^{+}\right)$496.2375, found 496.2376; IR (ATR) $1637(\mathrm{C}=\mathrm{O}), 3227 \mathrm{~cm}^{-1}(\mathrm{O}-\mathrm{H}) ; \mathrm{UV}$-vis $\left(\mathrm{CH}_{3} \mathrm{OH}\right) \lambda / \mathrm{nm},\left(\varepsilon / \mathrm{L} \mathrm{mol}^{-1} \mathrm{~cm}^{-1}\right) 381(910), 424(703) ;[\alpha]_{\mathrm{D}}=$ +6.7 ; HPLC: product eluted at $8.34 \mathrm{~min}$, approximately $70 \%$ pure by integration. 


\section{Acknowledgments}

This work was supported by grants from CSUPERB and the National Science Foundation (grant CHE-1058077)

Supporting Information Available. ${ }^{1} \mathrm{H}$ and ${ }^{13} \mathrm{C}$ NMR for tetrazanes 2a-i. ESR spectra and spectral simulations for verdazyls 3a-i. 


\section{References Cited}

1. $\quad$ Schlick, S., Advanced ESR methods in polymer research. Wiley: New York, 2006.

2. Yan, G.; Peng, L.; Jian, S.; Li, L.; Bottle, S. Chinese Science Bulletin 2008, 53 (24), 3777-3789.

3. $\quad$ Mravljak, J.; Ojstersek, T.; Pajk, S.; Sollner Dolenc, M. Tetrahedron Lett. 2013, 54 (38), 52365238.

4. $\quad$ Lin, F.; Pei, D.; He, W.; Huang, Z.; Huang, Y.; Guo, X. J. Mater. Chem. 2012, 22 (23), 1180111807.

5. $\quad$ Porel, M.; Jockusch, S.; Ottaviani, M. F.; Turro, N. J.; Ramamurthy, V. Langmuir 2011, 27 (17), 10548-10555.

6. Strashnikova, N. V.; Medvedeva, N.; Likhtenshtein, G. I. J. Biochem. Biophys. Methods. 2001, 48 (1), $43-60$.

7. $\quad$ Angelescu, D.; Vasilescu, M. J. Colloid Interface Sci. 2001, 244 (1), 139-144.

8. Green, S. A.; Morel, F. M. M.; Blough, N. V. Environmental Science \& Technology 1992, 26 (2), 294-302.

9. $\quad$ Green, S. A.; Simpson, D. J.; Zhou, G.; Ho, P. S.; Blough, N. V. J. Am. Chem. Soc. 1990, 112 (20), 7337-7346.

10. Pispisa, B.; Mazzuca, C.; Palleschi, A.; Stella, L.; Venanzi, M.; Wakselman, M.; Mazaleyrat, J. P.; Rainaldi, M.; Formaggio, F.; Toniolo, C. Chem.-Eur. J. 2003, 9 (17), 4084-4093.

11. Pispisa, B.; Palleschi, A.; Stella, L.; Venanzi, M.; Toniolo, C. J. Phys. Chem. B 1998, 102 (40), 7890-7898.

12. Stark, U.; Mueller-Warmuth, W. Ber. Bunsen-Ges. Phys. Chem. 1990, 94 (2), 168-72.

13. Fischer, H.; Tseng, L.-H.; Raitza, M.; Albert, K. Magn. Reson. Chem. 2000, 38 (5), 336-342.

14. Fischer, H. H.; Seiler, M.; Ertl, T. S.; Eberhardinger, U.; Bertagnolli, H.; Schmitt-Willich, H.; Albert, K. J. Phys. Chem. B 2003, 107 (20), 4879-4886.

15. Spirk, S.; Madl, T.; Pietschnig, R. Organometallics 2008, 27 (4), 500-502.

16. Endo, K.; Morishima, I.; Yonezawa, T. J. Chem. Phys. 1977, 67 (10), 4760-4767.

17. Braslau, R.; Rivera, F.; Lilie, E.; Cottman, M. J. Org. Chem. 2013, 78 (2), 238-245.

18. Lozinsky, E.; Martin, V. V.; Berezina, T. A.; Shames, A. I.; Weis, A. L.; Likhtenshtein, G. I. J. Biochem. Biophys. Methods. 1999, 38 (1), 29-42.

19. Matsuoka, Y.; Yamato, M.; Yamasaki, T.; Mito, F.; Yamada, K.-i. Free Radical Biol. Med. 2012, 53 (11), 2112-2118.

20. Sato, S.; Suzuki, M.; Soma, T.; Tsunoda, M. Spectrochim. Acta, Part A 2008, 70 (4), 799-804.

21. Han, H. F.; Zhang, G. X.; Wang, H. M. Chin. Sci. Bull. 2012, 57 (14), 1609-1611.

22. Rajca, A.; Wang, Y.; Boska, M.; Paletta, J. T.; Olankitwanit, A.; Swanson, M. A.; Mitchell, D. G.; Eaton, S. S.; Eaton, G. R.; Rajca, S. J. Am. Chem. Soc. 2012, 134 (38), 15724-15727.

23. Hyodo, F.; Matsumoto, K.; Matsumoto, A.; Mitchell, J. B.; Krishna, M. C. Cancer Res. 2006, 66, 9921.

24. Davis, R. M.; Matsumoto, S.; Bernardo, M.; Sowers, A.; Matsumoto, K.-I.; Krishna, M. C.; Mitchell, J. B. Free Radical Biology and Medicine 2011, 50 (3), 459-468.

25. Kuhn, R.; Fischer-Schwarz, G. Monatsh. Chem. 1966, 97, 517.

26. Bezvershenko, I. A.; Premyslov, V. K. Khim. Geterotsikl. Soedin. 1985, (8), 1129-30.

27. Barclay, T. M.; Hicks, R. G.; Lemaire, M. T.; Thompson, L. K.; Xu, Z. Q. Chem. Commun. 2002, (16), 1688-1689.

28. Paré, E. C.; Brook, D. J. R.; Brieger, A.; Badik, M.; Schinke, M. Org. Biomol. Chem. 2005, 3, 4258-4261. 
29. Le, T. N. T.; Brook, D. J. R., Water soluble Verdazyl Radicals synthesized from Aldoses. In 44th Western Regional Meeting of the American Chemical Society, Santa Clara, CA, United States, 2013.

30. Le, T. N. T.; Brook, D. J. R.; Vinhly, T.; Changcoco, V., Synthesis of verdazyl stable radicals from biomolecules. In 248th National meeting of the American Chemical Society, San Francisco, CA, 2014.

31. Barr, C. L.; Chase, P. A.; Hicks, R. G.; Lemaire, M. T.; Stevens, C. L. J. Org. Chem. 1999, 64, 8893.

32. Richardson, C.; Haller, B.; Brook, D. J. R.; Hundley, M.; Yee, G. T. Chem. Commun. 2010, $6590-6592$.

33. Neugebauer, F. A.; Fischer, H.; Siegel, R. Chem. Ber. 1988, 121, 815.

34. Brook, D. J. R.; Yee, G. T. J. Org. Chem. 2006, 71 (13), 4889-4895.

35. Gilroy, J. B.; McKinnon, S. D. J.; Koivisto, B. D.; Hicks, R. G. Org. Lett. 2007, 9 (23), 48374840 .

36. Gnewuch, T.; Sosnovsky, G. Chem. Rev. 1986, 86 (1), 203-238.

37. Osiecki, J. H.; Ullman, E. F. J. Am. Chem. Soc. 1968, 90 (4), 1078-1079.

38. Pütz, A.-M.; Schatzschneider, U.; Rentschler, E. Phys. Chem. Chem. Phys. 2012, 14 (5), 16491653.

39. Parker, C. A., Photoluminescence of Solutions Elsevier: Amsterdam, 1968.

40. Nakajima, A. Bull. Chem. Soc. Jpn. 1973, 46 (8), 2602-2604.

41. Drössler, P.; Holzer, W.; Penzkofer, A.; Hegemann, P. Chemical Physics 2002, 282 (3), 429439.

42. Giacobbe, E. M.; Mi, Q.; Colvin, M. T.; Cohen, B.; Ramanan, C.; Scott, A. M.; Yeganeh, S.; Marks, T. J.; Ratner, M. A.; Wasielewski, M. R. J. Am. Chem. Soc. 2009, 131 (10), 3700-3712. 